\title{
RAGE mediated intracellular $A \beta$ uptake contributes to the breakdown of tight junction in retinal pigment epithelium
}

\author{
Sung Wook Park ${ }^{1,2}$, Jin Hyoung Kim ${ }^{1}$, Sang Min Park ${ }^{3}$, Minho Moon ${ }^{4}$, Kihwang Lee ${ }^{5}$, \\ Kyu Hyung Park ${ }^{6,7}$, Woo Jin Park ${ }^{3}$ and Jeong Hun Kim ${ }^{1,2,6}$ \\ ${ }^{1}$ Fight against Angiogenesis-Related Blindness Laboratory, Biomedical Research Institute, Seoul National University Hospital, \\ Jongno-gu, Seoul, Korea \\ 2 Department of Biomedical Sciences, College of Medicine, Seoul National University, Daehak-ro, Jongno-gu, Seoul, Korea \\ ${ }^{3}$ Department of Life Sciences, Life Sciences Concentration GIST (Gwangju Institute of Science and Technology), Cheomdan- \\ gwagiro, Buk-gu, Gwangju, Korea \\ ${ }^{4}$ Department of Biochemistry, College of Medicine, Konyang University, Seo-gu, Daejeon, Korea \\ ${ }^{5}$ Department of Ophthalmology, Ajou University School of Medicine, Yeongtong-gu, Suwon-si, Gyeonggi-do, Korea \\ ${ }^{6}$ Department of Ophthalmology, College of Medicine, Seoul National University, Daehak-ro, Jongno-gu, Seoul, Korea \\ ${ }^{7}$ Department of Ophthalmology, Seoul National University Bundang Hospital, Gumiro, Bundang-gu, Seongnam, Gyeonggi- \\ do, Korea \\ Correspondence to: Jeong Hun Kim, email: steph25@snu.ac.kr
}

Keywords: amyloid $\beta$, age-related macular degeneration, endocytosis, tight junction, receptor for advanced glycation end products, Gerotarget

Received: September 10,2015 Accepted: September 22, $2015 \quad$ Published: September 29, 2015

This is an open-access article distributed under the terms of the Creative Commons Attribution License, which permits unrestricted use, distribution, and reproduction in any medium, provided the original author and source are credited.

\section{ABSTRACT}

Intracellular amyloid beta $(A \beta)$ has been implicated in neuronal cell death in Alzheimer's disease (AD). Intracellular $A \beta$ also contributes to tight junction breakdown of retinal pigment epithelium (RPE) in age-related macular degeneration (AMD). Although $A \beta$ is predominantly secreted from neuronal cells, the mechanism of $A \beta$ transport into RPE remains to be fully elucidated. In this study, we demonstrated that intracellular $A \beta$ was found concomitantly with the breakdown of tight junction in RPE after subretinal injection of $A \beta$ into the mouse eye. We also presented evidence that receptor for advanced glycation end products (RAGE) contributed to endocytosis of $A \beta$ in RPE. siRNA-mediated knockdown of RAGE prevented intracellular A $\beta$ accumulation as well as subsequent tight junction breakdown in RPE. In addition, we found that RAGE-mediated p38 MAPK signaling contributed to endocytosis of A $\beta$. Blockade of RAGE/p38 MAPK signaling inhibited $A \beta$ endocytosis, thereby preventing tight junction breakdown in RPE. These results implicate that intracellular $A \beta$ contributes to the breakdown of tight junction in RPE via the RAGE/p38 MAPK-mediated endocytosis. Thus, we suggest that RAGE could be a potential therapeutic target for intracellular $A \beta$ induced outer BRB breakdown in AMD.

\section{INTRODUCTION}

Age-related macular degeneration (AMD) is the leading cause of blindness in the elderly population and the prevalence is increasing in the world [1]. Drusen, a focal deposition of acellular debris between the retinal pigment epithelium (RPE) and Bruch's membrane, is the clinical hallmark and usually the initial clinical finding of
AMD. Amyloid $\beta(A \beta)$ is known to be found in drusen $[2,3]$. In addition, the deposition of $A \beta$ in the subRPE space is also concomitant with several features of AMD in a mouse model of Alzheimer disease (AD) $[4,5]$. It has been suggested that $A \beta$ in drusen may be an important contributor to the development of AMD.

Drusen in AMD and senile plaque cores in $\mathrm{AD}$ are similar in that deposition of $A \beta$ is found in extracellular 
space at later stages of both diseases. The role of extracellular A $\beta$ in RPE is known to alter the tight junction without apoptosis [6]. Recent studies, on the other hand, suggest that accumulation of intraneuronal $A \beta$ contributes neuronal apoptosis and may be an early event in the pathogenesis of $\mathrm{AD}[7,8]$. In this regard, we recently reported that intracellular $A \beta$ contributed to the breakdown of outer blood-retinal barrier (BRB) in 5XFAD mice, a mouse model of $\mathrm{AD}$, and suggested that intracellular $\mathrm{A} \beta$ could be also a key contributor to the development of AMD [9]. However, the precise mechanism of intracellular uptake of $A \beta$ in RPE remains to be elucidated.

Receptor for advanced glycation end products (RAGE), a member of the immunoglobulin superfamily, is a multi-ligand receptor capable of binding diverse range of molecules including $A \beta$ [10]. The receptor is known to be highly expressed in the RPE and levels of RAGE are significantly elevated in AMD, especially in RPE adjacent to drusen $[11,12]$. RAGE is also known to participate in the uptake of $A \beta$ from the circulation into the brain by endocytosis and transcytosis in endothelial cells [13, 14]. Recently, it has been suggested that RAGE-mediated signaling contributes to intraneuronal transport of $\mathrm{A} \beta$ [15]. Thus, we hypothesized that RAGE could contribute to intracellular transport of $A \beta$ in RPE. If $A \beta$ uptake is mediated by RAGE in RPE, anti-RAGE therapy could inhibit intracellular accumulation of $A \beta$, and subsequently prevent the breakdown of tight junction in RPE. This can expand the application of anti-RAGE therapy from AD to AMD [16, 17].

Herein, we demonstrate that subretinal injection of $A \beta$ leads to intracellular uptake of $A \beta$ and subsequent breakdown of tight junction in RPE in vivo. We also present evidence that extracellular $\mathrm{A} \beta$ gets translocated into intracellular space via RAGE-mediated endocytosis in RPE. The A $\beta /$ RAGE-mediated p38 MAPK signaling contributes to endocytosis of $A \beta$. Blocking of RAGE inhibits intracellular $A \beta$-induced tight junction breakdown in RPE. These findings indicate that RAGE contributes to the intracellular transport of $A \beta$, resulting in increased tight junction breakdown in RPE. Therefore, we suggest that blocking of RAGE can be a potential therapeutic target in AMD.

\section{RESULTS}

\section{Subretinal injection of $A \beta$ leads to intracellular A $\beta$ uptake and subsequent breakdown of tight junction in RPE}

We have recently demonstrated that $A \beta$, endogenously generated from 5 mutant transgenes, accumulated in intracellular space at the RPE layer with thickened Bruch's membrane and A $\beta$ deposits, thereby attenuating tight junction of RPE in aged 5XFAD mice [9]. Exogenous oligomeric $\mathrm{A} \beta(\mathrm{OA} \beta)_{42}$ injection into subretinal space is also known to break tight junctions of RPE and result in disorganized and irregular staining of both ZO-1 and occludin on days 3 to 15 post-injection in both young and aged mice [6]. These findings led us to probe whether extracellular $A \beta$ translocates into intracellular space and subsequently induces breakdown of tight junction of RPE in vivo.

To evaluate cellular uptake of $A \beta$ in RPE, we demonstrated intracellular $\mathrm{A} \beta$ uptake after subretinal injection of exogenous $\mathrm{OA} \beta_{42}$. Seven days after subretinal $\mathrm{OA} \beta_{42}$ injection, intracellular $A \beta_{42}$ was found concomitantly with the breakdown of tight junction (Figure 1). While typical hexagonal pattern of ZO-1 was not disrupted in vehicle injected mice (Figure 1A), the disrupted and irregular pattern of ZO-1 was found in $\mathrm{OA} \beta_{42}$ injected mice which indicated a breakdown of tight junction in RPE (Figure 1B). These specific changes of tight junction were shown in details (Figure 1C and 1D). We also confirmed the intracellular uptake of $\mathrm{A} \beta$ using FITC-labeled OA $\beta_{42}$ (Figure 1E). These data suggest that RPE uptakes exogenous $A \beta$, and this, in turn, leads to tight junction breakdown in vivo.

\section{Extracellular A $\beta$ translocates into intracellular space via RAGE-mediated endocytosis in RPE}

In order to determine the mechanism how extracellular $A \beta$ gets translocated into intracellular space in RPE, we demonstrated intracellular $A \beta$ uptake with plasma membrane and RAGE after exogenous OA $\beta_{42}$ treatment. First, we assessed intracellular distribution of $A \beta$ and biotinylated-cell surface protein after $A \beta$ treatment. After biotinylation of cell surface protein, cells were incubated with vehicle or $\mathrm{OA} \beta_{42}$ for $1 \mathrm{~h}$, and were treated with 2-mercaptoethanesulfonate (MesNa) to remove any remaining biotin on the cell surface. While control cells exposed to vehicle alone showed some biotinylated-proteins in cytosol (Figure 2A), RPE cells exposed to $\mathrm{OA} \beta_{42}$ showed significantly increased biotinylated-proteins in cytosol with intracellular $\mathrm{A} \beta$ (Figure 2B). Intriguingly, intracellular $A \beta$ was overlapped with some internalized biotinylated-proteins (Figure 2B, inset) suggesting that $A \beta$ could bind to cell surface protein and translocate into intracellular space together.

To access possible colocalization of RAGE and $\mathrm{A} \beta$, cells were incubated with vehicle or $\mathrm{OA} \beta_{42}$ for $1 \mathrm{~h}$, and the distribution of RAGE and $A \beta$ was examined under confocal microscope (Figure 2C and 2D). Indeed, the colocalization of RAGE and $A \beta$ was detected in RPE exposed to $\mathrm{OA} \beta_{42}$ (Figure 2D). These data suggested that $A \beta$ interacts with RAGE and is internalized into RPE.

To analyze the effect of intracellular $A \beta$ on tight junction integrity in RPE, we studied tight junction of RPE 
cells exposed to vehicle or $\mathrm{OA} \beta_{42}$ for $24 \mathrm{~h}$ (Figure $2 \mathrm{E}$ and $2 \mathrm{~F}$ ). Intracellular $\mathrm{A} \beta$ was concomitant with disrupted and disorganized ZO-1 expression (Figure 2F).

\section{siRNA-mediated knockdown of RAGE suppresses $A \beta$ uptake in RPE}

To investigate the role of RAGE on $A \beta$ uptake in RPE cells, we performed in vitro study in RPE cells treated with RAGE siRNA. siRNA-mediated knockdown effectively decreased $A G E R$ mRNA $(0.16 \pm 0.02$ fold induction) compared to negative siRNA $(1.00 \pm 0.13$, $p<0.05$; Figure 3A). In accordance with this result, it effectively decreased RAGE expression in RPE (Figure 3B). Then, we examined intracellular A $\beta$ uptake in RPE cells with RAGE siRNA. Interestingly, intracellular A $\beta$ uptake was decreased in RPE with RAGE siRNA compared to RPE with negative siRNA under confocal

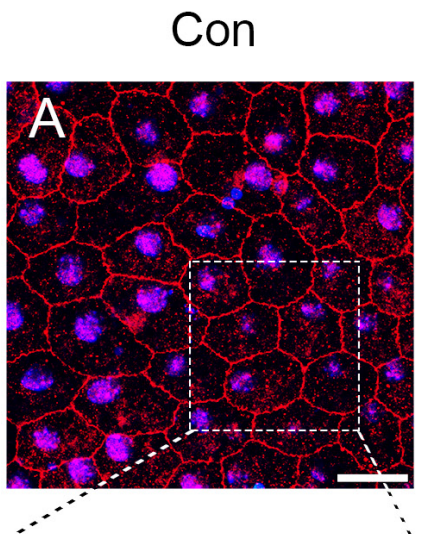

\section{Subretinal $O A \beta_{42}$}
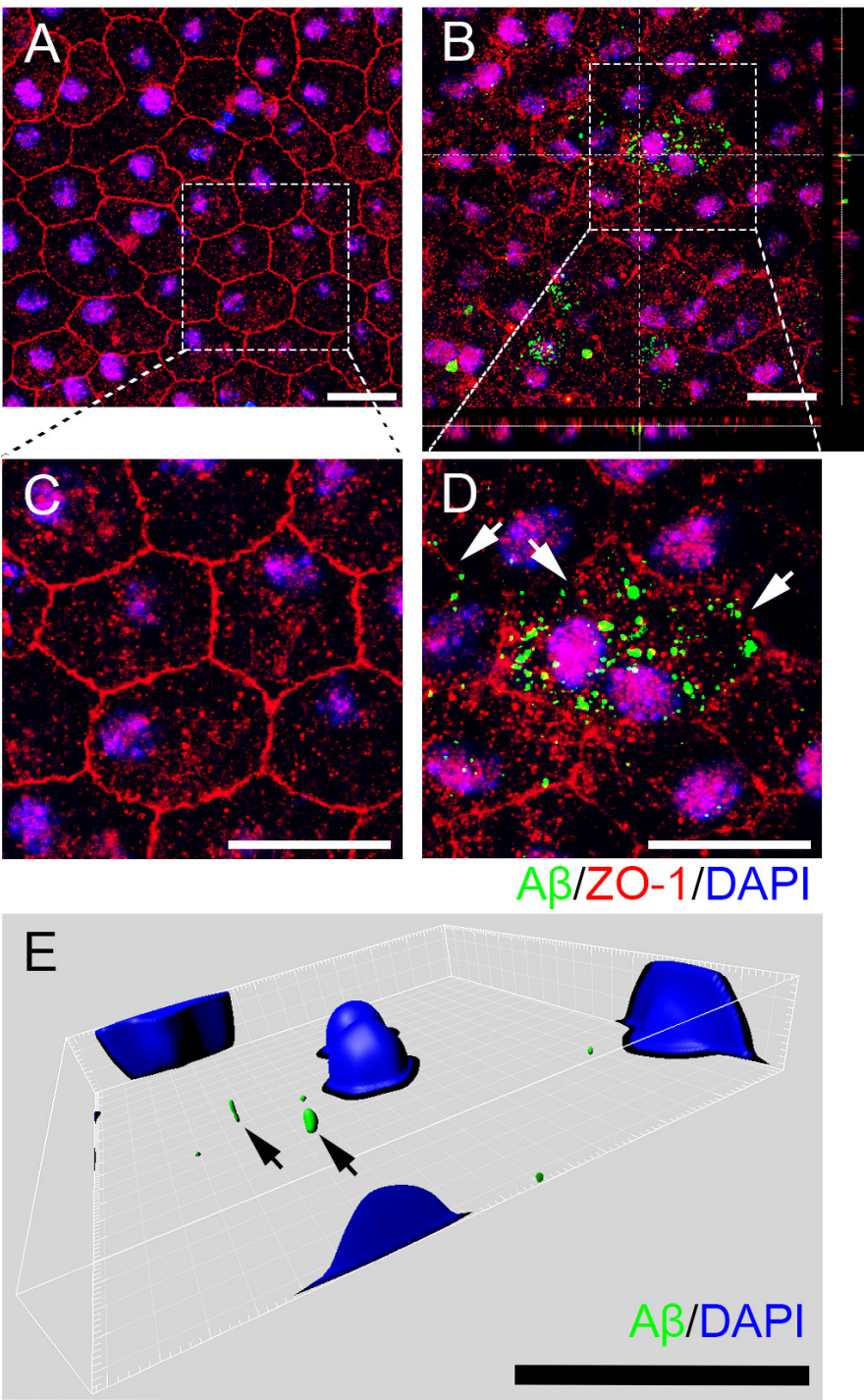

Figure 1: Subretinal injection of $A \beta$ leads to intracellular $A \beta$ uptake and subsequent breakdown of tight junction in RPE. Effect of subretinally injected $\mathrm{OA} \beta_{42}(1 \mu \mathrm{g})$ on tight junction in retinal pigment epithelium (RPE) flat mount was evaluated at 1 week post injection. A.-E. RPE flat mounts with immunofluorescence staining against A $\beta_{42}$ (green), tight junction protein $\mathrm{ZO}-1$ (red) and nucleus (DAPI, blue) are shown. A. RPE flat mount after subretinal vehicle injection (Con) shows tight junction with typical hexagonal shape. B. RPE flat mount after subretinal OA $\beta_{42}$ injection (Subretinal OA $\beta_{42}$ ) shows intracellular A $\beta$ and disrupted irregular expression of ZO-1. Orthogonal images indicates intracellular position of $A \beta$. C., D. Optical zoom: $\times 2.4$, a magnified portion of image a, b (enclosed in the white dotted box) to indicate intracellular $\mathrm{A} \beta$ and tight junction breakdown. D. Arrows indicate disrupted tight junctions. E. Representative images with 3-D reconstruction using Imaris software shows intracellular A $\beta$ in RPE layer after subretinal injection of FITC-labeled OA $\beta_{42}$ Arrows indicate intracellular A $\beta$ (green). Magnification, $\times 1000$. Scale bar $=20 \mu \mathrm{m}$. Figures were selected as representative data from three independent experiments. 
microscope (Figure 3C). Consistent with these data, western blot results also showed that intracellular $\mathrm{A} \beta$ was significantly decreased in RPE with RAGE siRNA compared to RPE with negative siRNA (Figure 3D and 3E). These data showed that siRNA-mediated knockdown of RAGE suppressed A $\beta$ uptake in RPE. This implied that RAGE played an important role in intracellular $A \beta$ uptake in RPE

\section{RAGE-mediated p38 MAPK signaling contributes to endocytosis of A $\beta$ in RPE}

RAGE is known to activate multiple downstream signaling pathways as a signal transduction receptor [18]. Based on the previous study [15], we demonstrated that A $\beta$-induced RAGE signaling activation might lead to $\mathrm{A} \beta$ uptake into RPE. We first examined the effect of $\mathrm{A} \beta$ treatment on phosphorylation of p38 MAPK. Treatment
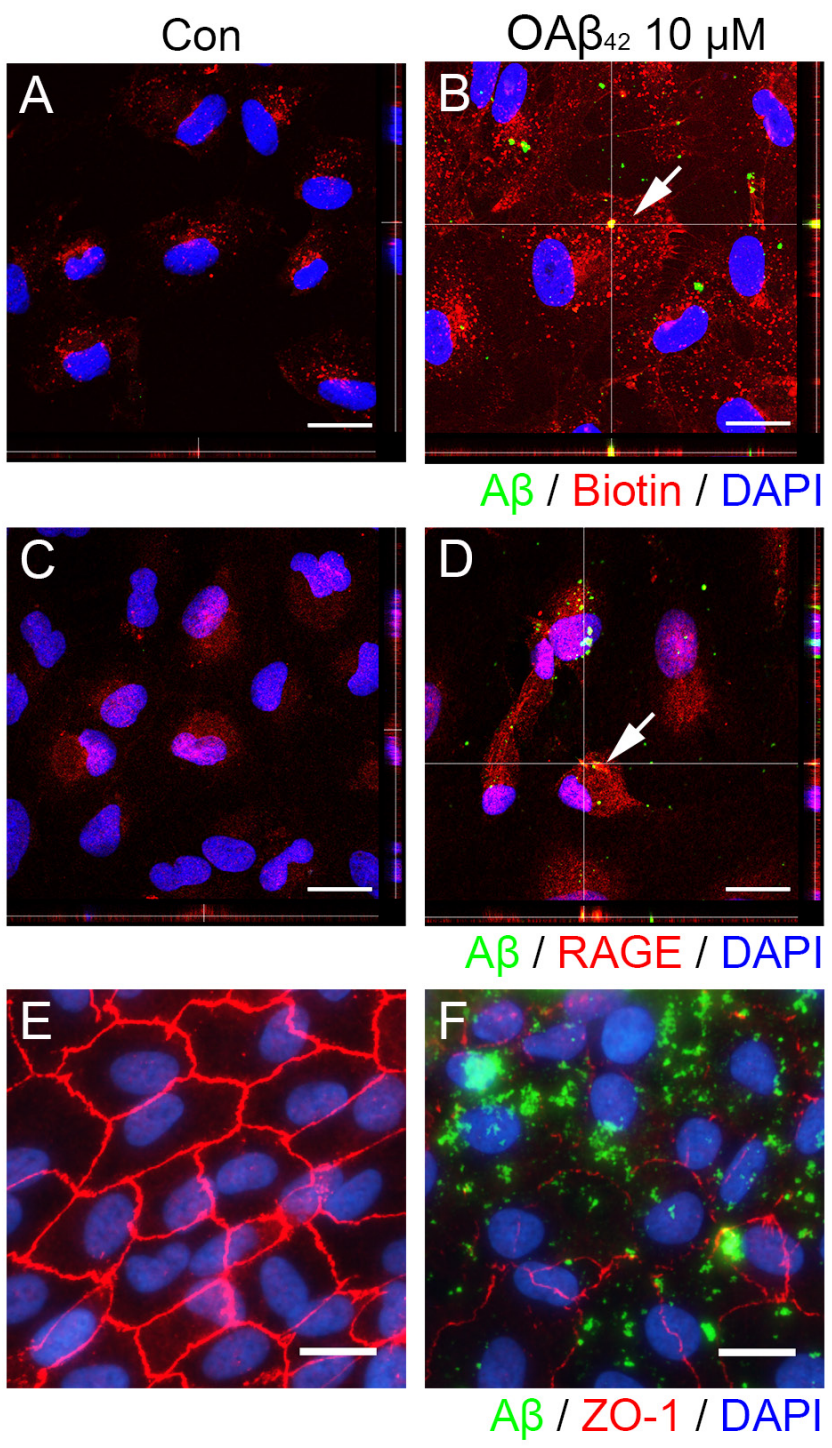

Figure 2: Extracellular A $\beta$ translocates into intracellular space via RAGE-mediated endocytosis in RPE. ARPE-19 cells were exposed to vehicle control A., C. or $\mathrm{OA} \beta_{42} 10 \mu \mathrm{M}(\mathrm{B}, \mathrm{D})$ for $60 \mathrm{~min}$, fixed in 4\% PFA, and stained by anti-human $\mathrm{A} \beta_{42}$ (green) and anti-biotin (red) or anti-RAGE (red). A. RPE cells shows basal level of endocytosis of cell membrane proteins (red). B. RPE cells treated with $\mathrm{OA} \beta_{42} 10 \mu \mathrm{M}$ shows increased level of endocytosis of cell membrane proteins (red) in orthogonal view with a $0.49 \mu \mathrm{m} Z$-step interval. A magnified portion of image B (enclosed in the white dotted box) indicates intracellular A $\beta$ merged with biotinylated membrane proteins. Arrow indicates intracellular colocalization of $A \beta$ and biotin. C. RPE cells shows RAGE expression. D. RPE cells treated with OA $\beta_{42}$ $10 \mu \mathrm{M}$ shows internalized RAGE (red) in orthogonal view. A magnified portion of image D (enclosed in the white dotted box) indicates intracellular A $\beta$ merged with internalized RAGE. Arrow indicates colocalization of A $\beta$ and RAGE. E., F. ARPE-19 cells were exposed to vehicle control E. or OA $\beta_{42} 10 \mu \mathrm{M}$ F. for $24 \mathrm{~h}$, fixed in 4\% PFA, and stained by anti-human A $\beta_{42}$ (green) and anti-ZO-1 (red). E. RPE cells show typical hexagonal shape tight junction. F. RPE cells show disintegrated and disorganized ZO-1 with intracellular A $\beta$. Magnification, $\times 1000$. Scale bar $=20 \mu \mathrm{m}$. Figures were selected as representative data from three independent experiments. 
A

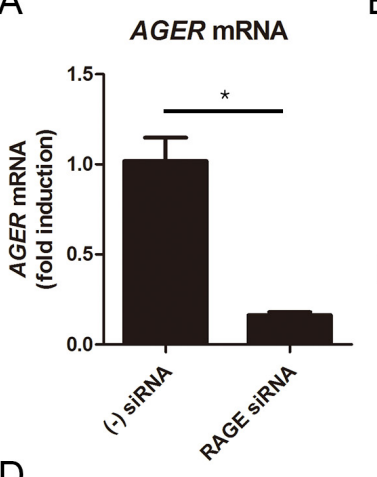

D

$\begin{array}{lllll}\text { OA }_{42} & - & - & + & + \\ \text { RAGE siRNA } & - & + & - & + \\ (-) \text { SiRNA } & + & - & + & -\end{array}$

B

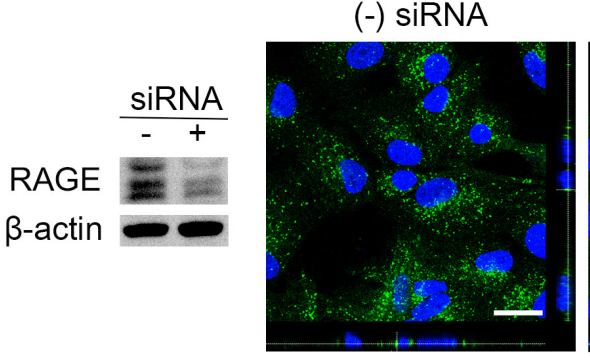

E
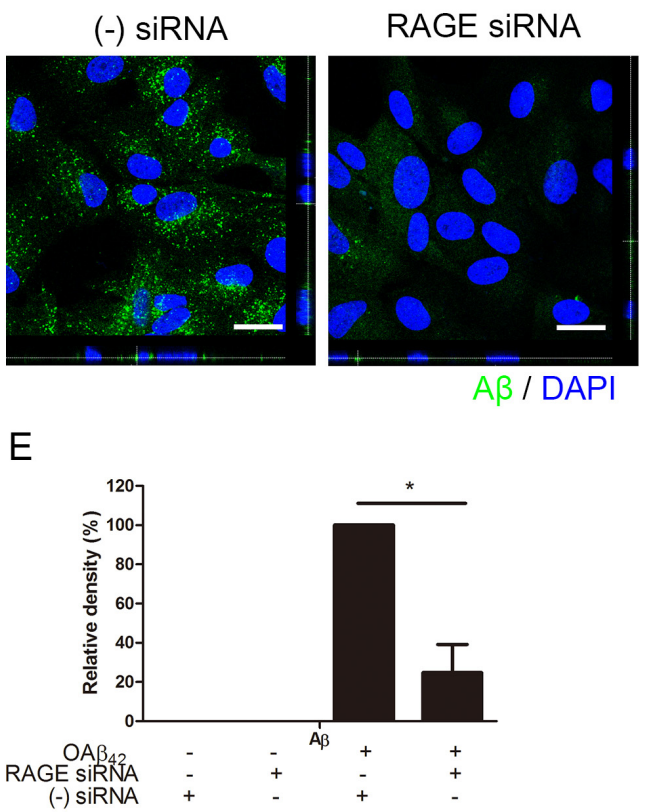

Figure 3: siRNA-mediated knockdown of RAGE suppresses A $\boldsymbol{\beta}$ uptake in RPE. RAGE siRNA was transfected in ARPE-19 cells. Negative siRNA was used as a control. RPE cells were treated OA $\beta_{42} 10 \mu \mathrm{M}$ for $24 \mathrm{~h}$. Intracellular A $\beta$ uptake is decreased in RPE with RAGE siRNA compared to RPE with negative siRNA. A. Relative expression of $A G E R$ mRNA is decreased in RPE cells with RAGE siRNA. B. RAGE expression is decreased in RPE cells with RAGE siRNA. C. Immunocytochemistry of A $\beta_{42}$ (green) shows decreased intracellular A $\beta$ in RPE cells with RAGE siRNA. D. Intracellular A $\beta$ was evaluated by Western blot. E. Relative band density of A $\beta$ was analyzed using ImageJ 1.42 software. $\beta$-actin was used as a loading control. Data are presented as mean \pm SEM. in graphs. $* p<0.05$ (two tailed, unpaired T-test). Figures were selected as representative data from three independent experiments.

\section{A}
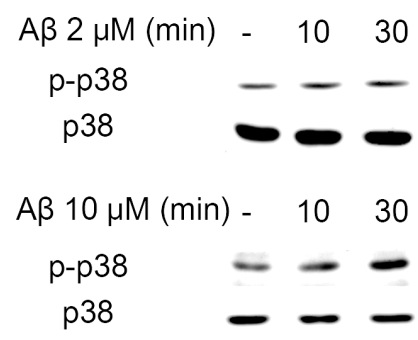

C

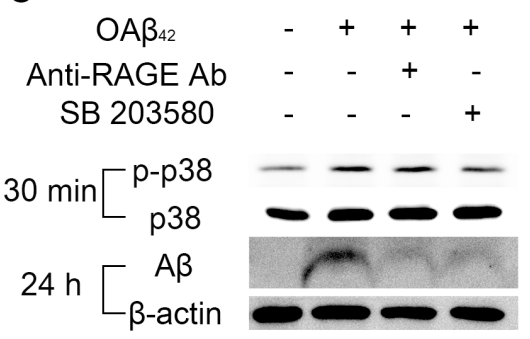

B

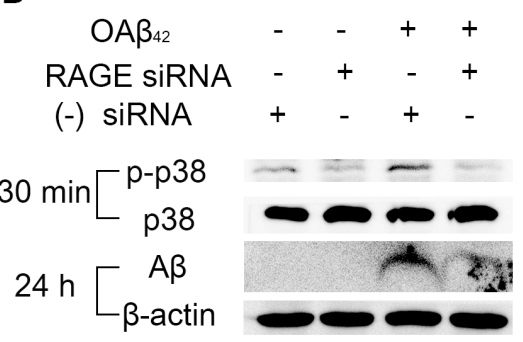

Figure 4: RAGE-mediated p38 MAPK signaling contributes to endocytosis of A $\boldsymbol{\beta}$ in $\mathbf{R P E}$. A. RPE cells were treated OA $\beta_{42}$ $2 \mu \mathrm{M}$ or $10 \mu \mathrm{M}$ for $30 \mathrm{~min}$. Phosphorylation of p38 MAPK is increased at $30 \mathrm{~min}$. B. RAGE siRNA was transfected in ARPE-19 cells. Negative siRNA was used as a control. RPE cells were treated $\mathrm{OA} \beta_{42} 10 \mu \mathrm{M}$ for indicated time (30 min and $\left.24 \mathrm{~h}\right)$. Phosphorylation of p38 MAPK and intracellular A $\beta$ uptake are decreased in RPE with RAGE siRNA compared to RPE with negative siRNA. C. RPE cells were pretreated with anti-RAGE neutralizing antibody $(20 \mu \mathrm{g} / \mathrm{ml}, 2 \mathrm{~h})$ and SB $203580(10 \mu \mathrm{M}, 30 \mathrm{~min})$ and were treated with $\mathrm{OA} \beta_{42} 10 \mu \mathrm{M}$ for indicated time (30 min and $24 \mathrm{~h}$ ). Anti-RAGE neutralizing antibody and SB 203580 decrease intracellular A $\beta$ in RPE. $\beta$-actin was used as an internal control. Figures were selected as representative data from three independent experiments. 
of $\mathrm{OA} \beta_{42}$ for $30 \mathrm{~min}$ showed a dose-dependent increase in phosphorylated p38 MAPK although it did not affect total protein levels of p38 MAPK (Figure 4A).

Next, we studied whether A $\beta$-induced phosphorylation of p38 MAPK is mediated by RAGE. RAGE siRNA effectively suppressed A $\beta$-induced p38 MAPK phosphorylation, and reduced intracellular $A \beta$ accumulation (Figure 4B). In addition, RPE cells pretreated with p38 MAPK inhibitor (SB 203580) showed strong inhibition of $A \beta$ uptake, similar to RPE cells pretreated with anti-RAGE neutralizing antibody (Figure
4C). Thus, $A \beta /$ RAGE-mediated p38 MAPK signaling contributes to intracellular $A \beta$ uptake in RPE.

\section{Blockade of RAGE inhibits intracellular A $\beta$ - induced tight junction breakdown in RPE}

To determine whether inhibition of intracellular $A \beta$ uptake could prevent $A \beta$-induced tight junction breakdown in RPE, we analyzed tight junction expression in RPE using western blot. We demonstrated that
A

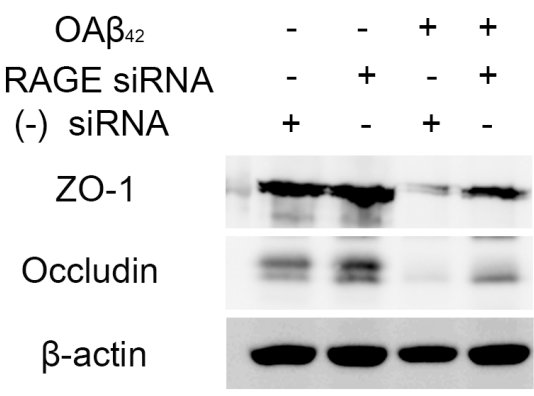

C

E

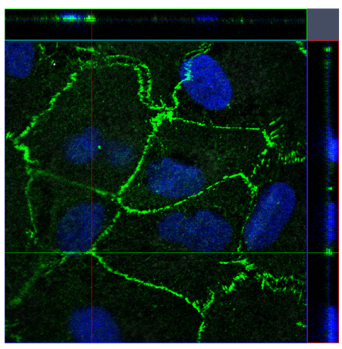

$O A \beta_{42}$

Anti-RAGE Ab SB 203580

Occludin

$\beta$-actin

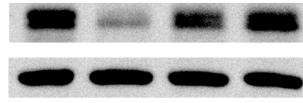

B
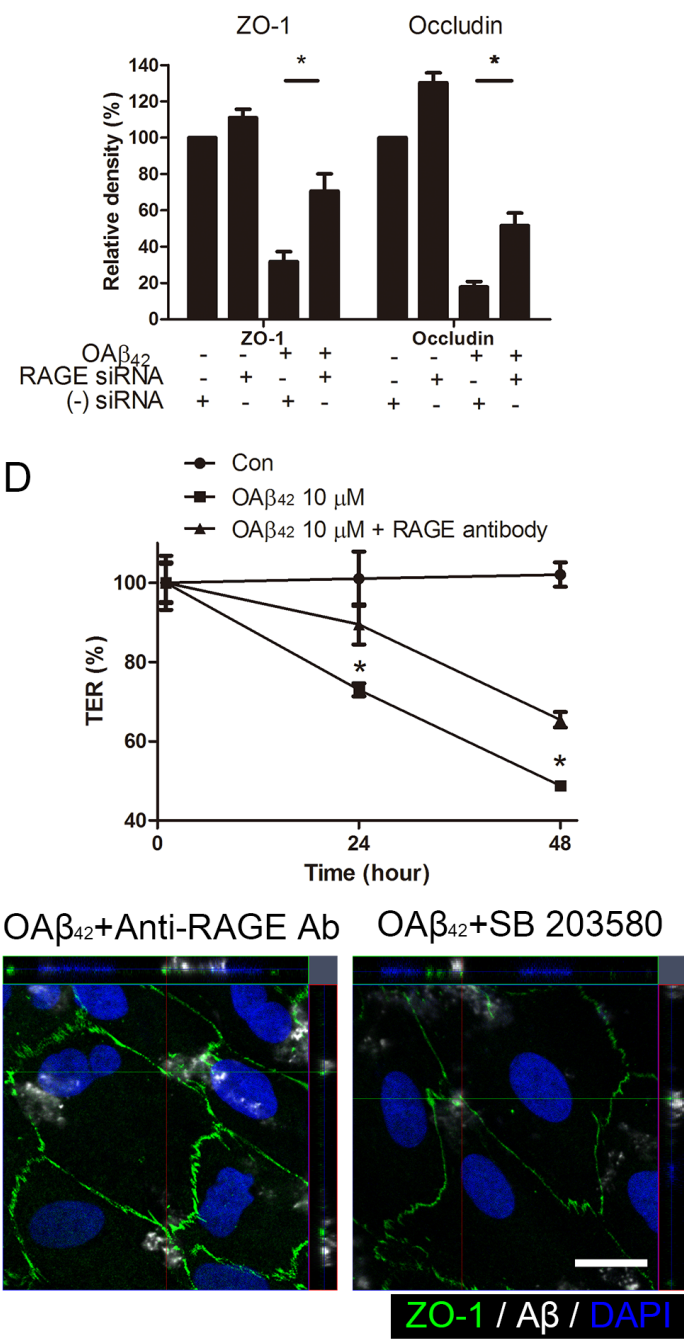

Figure 5: Blockade of RAGE inhibits intracellular A $\beta$-induced tight junction breakdown. A. RAGE siRNA was transfected in ARPE-19 cells. Negative siRNA was used as a control. RPE cells were treated OA $\beta_{42} 10 \mu \mathrm{M}$ for $24 \mathrm{~h}$. Tight junction proteins (ZO-1 and occludin) were evaluated by Western blot. $\beta$-actin was used as an internal control. B. Relative band density was analyzed using ImageJ 1.42 software. C. RPE cells were pretreated with anti-RAGE neutralizing antibody $(20 \mu \mathrm{g} / \mathrm{ml}, 2 \mathrm{~h})$ and SB $203580(10 \mu \mathrm{M}, 30 \mathrm{~min})$ and were treated with $\mathrm{OA}_{42} 10 \mu \mathrm{M}$ for $24 \mathrm{~h}$. Occludin was evaluated by Western blot. $\beta$-actin was used as an internal control. D. Transepithelial electrical resistance (TER) was measured for $48 \mathrm{~h}$ and normalized to the TER value just after A $\beta$ treatment. TER values with anti-RAGE neutralizing antibody (triangle) are compared to TER with $\mathrm{OA} \beta_{42}$ treatment alone (square) at indicated time point. Data are presented as mean \pm SEM. in graphs. ${ }^{*} p<0.05$ (two tailed, unpaired T-test). E. RPE cells were pretreated with anti-RAGE neutralizing antibody (20 $\mu \mathrm{g} / \mathrm{ml}, 2 \mathrm{~h}$ ) and SB $203580(10 \mu \mathrm{M}, 30 \mathrm{~min})$, and were treated with $\mathrm{OA}_{42} 10 \mu \mathrm{M}$ for $24 \mathrm{~h}$. Cells were stained by anti-human $\mathrm{A} \beta_{42}$ (white) and anti-ZO-1 (green). Magnification, $\times 1000$. Scale bar $=20 \mu \mathrm{m}$. Figures were selected as representative data from three independent experiments. 
intracellular uptake of exogenous $\mathrm{OA} \beta_{42}$ was decreased in RPE with siRNA-mediated knockdown of RAGE (Figure 4B). Indeed, siRNA-mediated knockdown of RAGE diminished the uptake of $A \beta$ which subsequently inhibited intracellular $A \beta$-induced tight junction breakdown in RPE (Figure 5A and 5B). Consistent with these data, treatment of p38 MAPK inhibitor (SB 203580) and anti-RAGE neutralizing antibody also showed protective effect on $A \beta$ induced decrease of occludin expression in RPE (Figure 5C).

To determine the role of RAGE on barrier function of RPE after A $\beta$ treatment, we measured transepithelial resistance (TER) in RPE for $48 \mathrm{~h}$. The mean initial TER of controls was $46 \pm 4.5 \mathrm{ohms} \cdot \mathrm{cm} 2$ when they reached a plateau. Anti-RAGE neutralizing antibody was sufficient to inhibit a decrease of TER during $48 \mathrm{~h}$ after $\mathrm{OA} \beta_{42}$ treatment ( $p<0.05$; Figure 5D). In addition, tight junction breakdown with ZO-1 disruption after OA $\beta_{42}$ was also attenuated when ARPE-19 cells were treated with either p38 MAPK inhibitor or anti-RAGE neutralizing antibody (Figure 5E). These data suggested that intracellular A $\beta$ uptake by RAGE contributed to breakdown of tight junction in RPE.

\section{DISCUSSION}

In this study, we demonstrated that subretinal injection of $A \beta$ led to intracellular uptake of $A \beta$ and subsequent breakdown of tight junction in RPE in vivo. We also showed that intracellular $A \beta$ contributed to breakdown of tight junction in RPE via the RAGE/p38 MAPK-mediated endocytosis. RAGE contributed to intracellular uptake of $A \beta$ which resulted in the increase of tight junction breakdown in RPE. Our study of the mechanism of intracellular $A \beta$ uptake in RPE might help to investigate the role of intracellular $A \beta$ in the pathogenesis of dry AMD. Furthermore, we also suggested that the research field of $A \beta$ should be expanded from $A D$ to $\mathrm{AMD}$, and from extracellular $\mathrm{A} \beta$ to intracellular $\mathrm{A} \beta$.

A growing body of evidence suggests that intraneuronal $A \beta$ contributes neuronal apoptosis in the early pathogenesis of $\mathrm{AD}[7,8]$. Intracellular $A \beta_{42}$ is known to accumulate in 5XFAD mice brain prior to plaque formation [19]. We hypothesized that intracellular A $\beta$ was also important in the early pathogenesis of AMD. However, the role of intracellular $A \beta$ in RPE was only described in our previous study suggesting that intracellular $A \beta$ in $\mathrm{RPE}$ could contribute to the development of AMD [9]. A $\beta$ is predominantly secreted from the neuronal cells, but the mechanism of $A \beta$ transport into the RPE remains to be fully elucidated in AMD.

Regarding to $A \beta$ uptake by RPE cells, the mechanism of intracellular uptake of exogenous $A \beta$ is not established. Although the main role of RPE is phagocytosis, RPE phagocytosis showed a remarkable specificity toward ROS via $\alpha v \beta 5$ integrin $[20,21]$. There were also several endocytotic pathways suggested as possible uptakes of $\mathrm{A} \beta$ in neurons and endothelial cells, including $\alpha 7-N A c h$ receptor [22], NMDA receptor [23], LDL receptor-related protein 1 [24], and RAGE [14]. Among these candidates, we demonstrated that RAGE contributed to intracellular $A \beta$ uptake in RPE. RAGE is also important in retinal aging [25]. It is known that RAGE distributed at apical membrane of the RPE $[11,26]$. In line with our results, $A \beta /$ RAGE-mediated p38 MAPK signaling contributes to $A \beta$ transport and neuronal dysfunction [15]. Activation of endocytosis is essential in regulating the p38 MAPK activity in endothelial cells [27]. Despite the evident role of RAGE in endocytosis of $A \beta$ in this study, phagocytosis or other receptor mediated endocytosis could also contribute to intracellular uptake of $A \beta$. In addition, we also hypothesized that RAGE-mediated signaling itself (i.e. GSK-3 $\beta$ or $\mathrm{NF}-\kappa \mathrm{B}$ related signaling pathway) could affect tight junction or $A \beta$-related pathology in RPE. Thus, those $A \beta$-related mechanisms on RPE pathology should be investigated in further study.

The limitation of the study is that ARPE19 cells generate less effective tight junction than human fetal RPE (hfRPE) cells for in vitro study. It is also known that the staining with occludin in ARPE-19 cells is not good as that in hfRPE [28]. Thus, it is better to show the distribution of ZO-1 tight junction protein in immunocytochemistry for tight junction evaluation in ARPE-19 cells. Nonetheless, this study for the first time demonstrated that intracellular A $\beta$ uptake was mediated by RAGE via the RAGE/p38 MAPK-mediated endocytosis in RPE.

In conclusion, intracellular $A \beta$ uptake was mediated by RAGE in RPE. Intracellular A $\beta$ contributed to breakdown of tight junction in RPE via the RAGE/ p38 MAPK-mediated endocytosis. Blockade of RAGE with anti-RAGE antibody could block the intracellular accumulation of $A \beta$, and subsequently prevent the breakdown of tight junction in RPE. Thus, we suggest that blockade of RAGE can be a potential therapeutic target in AMD. Further study is warranted to develop new modality of RAGE-specific inhibitor for the treatment of AMD.

\section{MATERIALS AND METHODS}

\section{Animals}

All animal experiments in this study were in strict agreement with the Association for Research in Vision and Ophthalmology Statement for the Use of Animals in Ophthalmic and Vision Research and the guidelines of the Seoul National University Animal Care and Use Committee. Six-week-old, pathogen-free male C57BL/6J mice were purchased from Central Lab (Seoul, Korea). 


\section{Reagents and antibodies}

Rabbit anti-ZO-1 and anti-occludin antibodies, Lipofectamine RNAi max and other culture reagents were purchased from Life technologies (Gaithersburg, MD, USA). Anti-p38, anti-phospho p38, and anti- $\beta$ actin antibodies were purchased from Cell Signaling Technology Inc. (Beverly, MA, USA). Mouse anti-A $\beta_{42}$ (12F4) antibody was purchased from Covance (Seoul, Korea). SB 203580 was purchased from EMD Millipore (Billerica, MA, USA). Anti-RAGE neutralizing mAb (MAB11451) and anti-RAGE antibody (AF1145) were purchased from R\&D system Inc. (Minneapolis, MN, USA). EZ-Link Sulfo-NHS-SS-Biotin (Cat \#21328) was purchased from Pierce Biotechnology Inc. (Rockford, IL, USA). RAGE siRNA and control negative siRNA were purchased from Bioneer (Daejeon, Korea). A $\beta_{42}$ and FITC labeled $\mathrm{A} \beta_{42}$ were purchased from American peptide company Inc. (Sunnyvale, CA, USA).

\section{Cell cultures and siRNA transfection}

ARPE-19 cells (American Type Culture Collection, Manassas, VA, USA) were used for human RPE cells. The cells were routinely maintained in DMEM/F12 containing $10 \% \mathrm{FBS}, 100 \mathrm{U} / \mathrm{mL}$ penicillin, and $100 \mu \mathrm{g} /$ $\mathrm{mL}$ streptomycin. RAGE siRNA and negative siRNA (50 $\mathrm{nM}$ ) were transfected using Lipofectamine RNAi max in opti-MEM ${ }^{\circledR}$ media according to the manufacturer's instructions. After reaching confluent, ARPE-19 cells were maintained in DMEM/F12 containing 1\% FBS to make a polarization for the experiments [29].

\section{Preparation of oligomeric A $\beta 42$ solution}

$\mathrm{OA} \beta_{42}$ solution were generated as the previously described method [9]. $A \beta_{42}$ and FITC labeled $A \beta_{42}$ (62$0-80 \mathrm{~B}$ and $62-0-82 \mathrm{~B}$ ) were dissolved in hexafluoro-2propanol (Sigma Aldrich, St. Louis, MO, USA) to a final concentration of $1 \mathrm{mg} / \mathrm{ml}$ at RT for 3 days. The peptide was aliquoted and dried under vacuum for $1 \mathrm{~h}$. The aliquoted peptide was dissolved in DMSO to a final concentration of $2 \mathrm{mM}$. The protein concentration was measured using a BCA protein assay kit (Pierce Biotechnology Inc.). The $\mathrm{A} \beta_{42}$ stock in DMSO was diluted directly into DMEM/F12 at $10 \mu \mathrm{M}$, and incubated for $24 \mathrm{~h}$ at $4{ }^{\circ} \mathrm{C}$ to make $\mathrm{OA} \beta_{42}$.

\section{Subretinal injection}

Twenty-week-old C57BL/6J mice were deeply anesthetized using a mixture of Zoletil $50^{\circledR}$ (Virbac, Carros, France) and Rompun ${ }^{\circledR}$ (Bayer Korea, Seoul, Korea) (3:1 ratio, $1 \mathrm{ml} / \mathrm{kg}$, i.p.). Then subretinal injection of $2 \mathrm{uL}$ of $100 \mu \mathrm{M} \mathrm{OA} \beta_{42}$ was performed using Nanofil syringe with
33 G blunt needle (World Precision Instruments Inc., Sarasota, FL, USA) under operating microscope (Leica Microsystems Ltd. Seoul, Korea). For the control mice, only $2 \mathrm{uL}$ of DMEM/F12 media without $\mathrm{A} \beta$ was injected as a vehicle.

\section{Immunofluorescence staining}

C57BL6/J mice $(n=12)$ were sacrificed 1 week after subretinal injection of $\mathrm{OA} \beta_{42}$. After deep anesthesia, mice were sacrificed and globes were enucleated. Enucleated eyes were fixed in $4 \%$ paraformaldehyde for $24 \mathrm{~h}$. For the flat mount of RPE/choroid complex, enucleated eyes were dissected out to remove neural retina, the RPE/ choroid complex were gently flat mounted and fixed in methanol for 15 min at $-20^{\circ} \mathrm{C}$. After washing with PBS, $\mathrm{RPE} /$ choroid complex was incubated in Perm/Block solution $(0.2 \%$ Triton-X 100 and $0.3 \%$ BSA in PBS) at RT for $1 \mathrm{~h}$. Then, it was incubated overnight at $4{ }^{\circ} \mathrm{C}$ with primary antibodies against rabbit anti-ZO-1 (1:100) and mouse anti-A $\beta_{42}(1: 100)$. After washing with PBS, it was incubated at RT for $1 \mathrm{~h}$ with secondary antibodies (Alexa Fluor 488 donkey anti-mouse IgG, 1:200 and Alexa Fluor 594 donkey anti-rabbit Ig G, 1:200). After washing with PBS, it was counterstained with $10 \mathrm{mg} / \mathrm{ml}$ DAPI (Sigma Aldrich). After washing with PBS, the RPE/choroid complex was mounted with Fluoromount ${ }^{\mathrm{TM}}$ Aqueous Mounting Medium (Sigma Aldrich) and observed under confocal microscope (Leica TCS STED, Leica Microsystems Ltd.).

\section{Biotinylation of membrane proteins}

Biotinylation of cell membrane proteins was performed as previously described method [15]. ARPE19 cells plated in 8-well culture slides were washed with PBS and incubated with PBS containing $300 \mu \mathrm{g} / \mathrm{mL}$ sulfoNHS-SS-biotin at RT for $30 \mathrm{~min}$. The biotinylation of membrane proteins was quenched using $1 \mathrm{M}$ glycine in PBS at $4{ }^{\circ} \mathrm{C}$ for $15 \mathrm{~min}$. After additional two brief wash with $100 \mathrm{mM}$ glycine in PBS to remove the residual biotin, cells were incubated with $\mathrm{OA} \beta_{42}$ at $37^{\circ} \mathrm{C}$ for $1 \mathrm{~h}$. Then, to terminate uptake of biotinylated proteins, cells were washed with cold NT buffer $(150 \mathrm{mM} \mathrm{NaCl}, 1 \mathrm{mM}$ EDTA, 0.2\% BSA, and $20 \mathrm{mM}$ Tris, $\mathrm{pH}$ 8.6). Then, cells were incubated with $50 \mathrm{mM} \mathrm{MesNa/NT}$ buffer at $4{ }^{\circ} \mathrm{C}$ for $30 \mathrm{~min}$.

\section{Immunocytochemistry}

ARPE-19 cells with confluence were incubated with $\mathrm{OA}_{42}(10 \mu \mathrm{M})$ in serum free DMEM/F12 medium for $24 \mathrm{~h}$. After removal of the medium, cells were intensively washed with warm PBS and fixed 
with $4 \%$ paraformaldehyde at RT for $15 \mathrm{~min}$. For the permeabilization, $0.2 \%$ Triton X-100 in PBS was treated for $10 \mathrm{~min}$. After washing, the cells were incubated with $1 \% \mathrm{BSA}$ in PBS at RT for $1 \mathrm{~h}$. Cells were incubated overnight at $4{ }^{\circ} \mathrm{C}$ with rabbit anti-ZO-1 (1:1000), mouse anti-A $\beta$ (1:1000) and goat anti-RAGE (1:500). After washing, cells were incubated at RT for $1 \mathrm{~h}$ with secondary antibodies (Alexa Fluor 488, 594, 647 anti-mouse, rabbit, goat IgG, 1:500). Nucleus was counterstained with DAPI at RT for $10 \mathrm{~min}$. After washing, the slides were mounted and observed under confocal microscope (Leica TCS STED).

\section{Western blotting}

ARPE-19 cells were incubated with $10 \mu \mathrm{M} \mathrm{OA} \beta_{42}$ for $30 \mathrm{~min}$ to detect p38 MAPK and for $24 \mathrm{~h}$ to detect intracellular A $\beta$ and tight junction proteins. SB 203580 (10 $\mu \mathrm{M}$, p38 MAPK inhibitor, EMD Millipore, 559395) was pretreated $30 \mathrm{~min}$ prior to $\mathrm{OA} \beta_{42}$ treatment. Anti-RAGE neutralizing antibody $(20 \mu \mathrm{g} / \mathrm{ml})$ was pretreated $2 \mathrm{~h}$ prior to $\mathrm{OA} \beta_{42}$ treatment. Cell proteins were extracted with RIPA buffer (Tris 50mM pH 7.4; $\mathrm{NaCl} 150 \mathrm{mM}$; SDS 0.1\%; NaDeoxycholate $0.5 \%$; Triton X-100 1\%) with a complete protease inhibitor cocktail (Roche, Indianapolis, IN, USA). Twenty five micrograms of protein was separated by SDSPAGE, and transferred to nitrocellulose membranes (GE healthcare life sciences, Piscataway, NJ, USA). After blocking in 5\% BSA in PBST (0.1\% Tween 20 in PBS), the membranes were incubated with primary antibodies for p38 (1:1,000), phospho-p38 (1:1,000), ZO-1 (1:1,000), occludin (1:2,000), $A \beta_{42}(1: 1000)$ and actin $(1: 5,000)$. The membranes were incubated with ECL substrate (DoGEN, Seoul, Korea) and exposed in ImageQuant ${ }^{\mathrm{TM}}$ LAS 4000 (GE healthcare life sciences). The band intensity analyzed using ImageJ 1.42 software (National Institutes of Health, Bethesda, MD, USA).

\section{Transepithelial electrical resistance measurement}

The measurement of TER was performed by impedance analysis using EVOM2 TER (World Precision Instruments). Briefly, the cell covered transwell filters $(0.4$ $\mu \mathrm{m}$, Corning Inc., NY, USA) coated with laminin were placed in this setup using 12-well plate. After stabilization of TER value on plateau, TER was measured with 10 $\mu \mathrm{M} \mathrm{OA} \beta_{42}$ and anti-RAGE neutralizing antibody (20 $\mu \mathrm{g} / \mathrm{ml}$ ) for $48 \mathrm{~h}$. The TER value just after treatment was normalized to $100 \%$ for relative analysis.

\section{Real-time PCR}

Total RNA was isolated from RPE cells using TRIzol reagent according to the manufacturer's instructions. cDNA was prepared with High Capacity RNA-to-cDNA kit. Real-time PCR was performed with StepOnePlus Real-time PCR System with TaqMan ${ }^{\circledR}$ Fast Advanced Master Mix and specific Gene Expression Assays (AGER and GAPDH). All procedures were performed in accordance with the MIQE guidelines. All material and machine used in Real-time PCR was purchased from Life Technologies.

\section{Statistical analysis}

Statistical analyses were performed using SPSS software version 18.0 (SPSS Inc., Chicago, IL, USA). Two-tailed unpaired T-test was used. $P$ values less than 0.05 were considered to be statistically significant. Data and figures are depicted as mean $\pm \mathrm{SEM}$.

\section{ACKNOWLEDGMENTS AND GRANT SUPPORT}

This study was supported by the Seoul National University Research Grant (800-20140542), the MD-PhD program of Korea Research Institute of Bioscience and Biotechnology (700-2015-2018), the Pioneer Research Program of the National Research Foundation of Korea/ Ministry of Education, Science and Technology (20120009544), the Bio \& Medical Technology Development Program of the National Research Foundation funded by the Korean government, MSIP (NRF2015M3A9E6028949).

\section{CONFLICTS OF INTEREST}

The authors declare that they have no conflict of interest.

\section{REFERENCES}

1. Jager RD, Mieler WF and Miller JW. Age-related macular degeneration. N Engl J Med. 2008; 358:2606-2617.

2. Johnson LV, Leitner WP, Rivest AJ, Staples MK, Radeke MJ and Anderson DH. The Alzheimer's A beta -peptide is deposited at sites of complement activation in pathologic deposits associated with aging and age-related macular degeneration. Proc Natl Acad Sci U S A. 2002; 99:1183011835 .

3. Dentchev T, Milam AH, Lee VM, Trojanowski JQ and Dunaief JL. Amyloid-beta is found in drusen from some age-related macular degeneration retinas, but not in drusen from normal retinas. Mol Vis. 2003; 9:184-190.

4. Yoshida T, Ohno-Matsui K, Ichinose S, Sato T, Iwata N, Saido TC, Hisatomi T, Mochizuki M and Morita I. The potential role of amyloid beta in the pathogenesis of age-related macular degeneration. J Clin Invest. 2005; 
115:2793-2800.

5. Ding JD, Johnson LV, Herrmann R, Farsiu S, Smith SG, Groelle M, Mace BE, Sullivan P, Jamison JA, Kelly U, Harrabi O, Bollini SS, Dilley J, et al. Anti-amyloid therapy protects against retinal pigmented epithelium damage and vision loss in a model of age-related macular degeneration. Proc Natl Acad Sci U S A. 2011; 108:E279-287.

6. Bruban J, Glotin AL, Dinet V, Chalour N, Sennlaub F, Jonet L, An N, Faussat AM and Mascarelli F. Amyloid-beta(1-42) alters structure and function of retinal pigmented epithelial cells. Aging Cell. 2009; 8:162-177.

7. LaFerla FM, Green KN and Oddo S. Intracellular amyloidbeta in Alzheimer's disease. Nat Rev Neurosci. 2007; 8:499-509.

8. Wirths $\mathrm{O}$ and Bayer TA. Intraneuronal Abeta accumulation and neurodegeneration: lessons from transgenic models. Life Sci. 2012; 91:1148-1152.

9. Park SW, Kim JH, Mook-Jung I, Kim KW, Park WJ, Park $\mathrm{KH}$ and $\mathrm{Kim} \mathrm{JH}$. Intracellular amyloid beta alters the tight junction of retinal pigment epithelium in 5XFAD mice. Neurobiol Aging. 2014; 35:2013-2020.

10. Chaney MO, Stine WB, Kokjohn TA, Kuo YM, Esh C, Rahman A, Luehrs DC, Schmidt AM, Stern D, Yan SD and Roher AE. RAGE and amyloid beta interactions: atomic force microscopy and molecular modeling. Biochim Biophys Acta. 2005; 1741:199-205.

11. Howes KA, Liu Y, Dunaief JL, Milam A, Frederick JM, Marks A and Baehr W. Receptor for advanced glycation end products and age-related macular degeneration. Invest Ophthalmol Vis Sci. 2004; 45:3713-3720.

12. Yamada Y, Ishibashi K, Ishibashi K, Bhutto IA, Tian J, Lutty GA and Handa JT. The expression of advanced glycation endproduct receptors in rpe cells associated with basal deposits in human maculas. Exp Eye Res. 2006; 82:840-848

13. Mackic JB, Stins M, McComb JG, Calero M, Ghiso J, Kim KS, Yan SD, Stern D, Schmidt AM, Frangione B and Zlokovic BV. Human blood-brain barrier receptors for Alzheimer's amyloid-beta 1- 40. Asymmetrical binding, endocytosis, and transcytosis at the apical side of brain microvascular endothelial cell monolayer. J Clin Invest. 1998; 102:734-743.

14. Deane R, Du Yan S, Submamaryan RK, LaRue B, Jovanovic S, Hogg E, Welch D, Manness L, Lin C, Yu J, Zhu H, Ghiso J, Frangione B, et al. RAGE mediates amyloid-beta peptide transport across the blood-brain barrier and accumulation in brain. Nat Med. 2003; 9:907913.

15. Takuma K, Fang F, Zhang W, Yan S, Fukuzaki E, Du H, Sosunov A, McKhann G, Funatsu Y, Nakamichi N, Nagai T, Mizoguchi H, Ibi D, et al. RAGE-mediated signaling contributes to intraneuronal transport of amyloid-beta and neuronal dysfunction. Proc Natl Acad Sci U S A. 2009; 106:20021-20026.
16. Deane R, Singh I, Sagare AP, Bell RD, Ross NT, LaRue B, Love R, Perry S, Paquette N, Deane RJ, Thiyagarajan M, Zarcone T, Fritz G, et al. A multimodal RAGE-specific inhibitor reduces amyloid beta-mediated brain disorder in a mouse model of Alzheimer disease. J Clin Invest. 2012; 122:1377-1392.

17. Galasko D, Bell J, Mancuso JY, Kupiec JW, Sabbagh MN, van Dyck C, Thomas RG, Aisen PS and Alzheimer's Disease Cooperative S. Clinical trial of an inhibitor of RAGE-Abeta interactions in Alzheimer disease. Neurology. 2014; 82:1536-1542.

18. Chen X, Walker DG, Schmidt AM, Arancio O, Lue LF and Yan SD. RAGE: a potential target for Abeta-mediated cellular perturbation in Alzheimer's disease. Curr Mol Med. 2007; 7:735-742.

19. Moon M, Hong HS, Nam DW, Baik SH, Song H, Kook SY, Kim YS, Lee J and Mook-Jung I. Intracellular amyloid-beta accumulation in calcium-binding protein-deficient neurons leads to amyloid-beta plaque formation in animal model of Alzheimer's disease. J Alzheimers Dis. 2012; 29:615-628.

20. Mayerson PL and Hall MO. Rat retinal pigment epithelial cells show specificity of phagocytosis in vitro. J Cell Biol. 1986; 103:299-308.

21. Finnemann SC, Bonilha VL, Marmorstein AD and Rodriguez-Boulan E. Phagocytosis of rod outer segments by retinal pigment epithelial cells requires alpha(v)beta5 integrin for binding but not for internalization. Proc Natl Acad Sci U S A. 1997; 94:12932-12937.

22. Nagele RG, D‘Andrea MR, Anderson WJ and Wang HY. Intracellular accumulation of beta-amyloid(1-42) in neurons is facilitated by the alpha 7 nicotinic acetylcholine receptor in Alzheimer's disease. Neuroscience. 2002; 110:199-211.

23. Bi X, Gall CM, Zhou J and Lynch G. Uptake and pathogenic effects of amyloid beta peptide 1-42 are enhanced by integrin antagonists and blocked by NMDA receptor antagonists. Neuroscience. 2002; 112:827-840.

24. Deane R, Wu Z, Sagare A, Davis J, Du Yan S, Hamm K, Xu F, Parisi M, LaRue B, Hu HW, Spijkers P, Guo H, Song $\mathrm{X}$, et al. LRP/amyloid beta-peptide interaction mediates differential brain efflux of Abeta isoforms. Neuron. 2004; 43:333-344.

25. Glenn JV and Stitt AW. The role of advanced glycation end products in retinal ageing and disease. Biochim Biophys Acta. 2009; 1790:1109-1116.

26. Dahrouj M, Alsarraf O, Liu Y, Crosson CE and Ablonczy Z. C-type natriuretic peptide protects the retinal pigment epithelium against advanced glycation end product-induced barrier dysfunction. J Pharmacol Exp Ther. 2013; 344:96102.

27. Siddiqui SS, Siddiqui ZK, Uddin S, Minshall RD and Malik AB. p38 MAPK activation coupled to endocytosis is a determinant of endothelial monolayer integrity. Am J Physiol Lung Cell Mol Physiol. 2007; 292:L114-124.

28. Ablonczy Z, Dahrouj M, Tang PH, Liu Y, Sambamurti K, 
Marmorstein $\mathrm{AD}$ and Crosson CE. Human retinal pigment epithelium cells as functional models for the RPE in vivo. Invest Ophthalmol Vis Sci. 2011; 52:8614-8620.

29. Mitter SK, Song C, Qi X, Mao H, Rao H, Akin D, Lewin A, Grant M, Dunn W, Jr., Ding J, Bowes Rickman C and Boulton M. Dysregulated autophagy in the RPE is associated with increased susceptibility to oxidative stress and AMD. Autophagy. 2014; 10:1989-2005. 